\title{
Effect of different mulching and irrigation scheduling on agronomical parameters of bokchoy
}

R. A. Pachore, S. A. Bhukele, S. S. Deshpande and S. P. Jadhav

Received : 20.12.2018; Revised : 12.02.2019; Accepted : 02.03.2019

See end of the Paper for authors' affiliation

Correspondence to :

\section{R.A. Pachore}

Department of Irrigation and Drainage Engineering,

K.K.Wagh College of Agricultural Engineering and Technology, Nashik (M.S.) India

Email : rahulpachore07

@ gmail.com
- ABSTRACT : A field experiment was conducted to study the Bokchoy productivity under drip irrigation with different mulching at Mhasrul farm of K. K. Wagh College of Agricultural Engineering and Technology, Nashik during February 2018 to March 2018. The experiment was laid out in Randomized Block Design with six treatments. In the experiment, the maximum yield was obtained from plastic mulch with 100 per cent irrigation treatment $(270 \mathrm{~g})$ while minimum yield was obtained from without mulch with 100 per cent irrigation treatment $(40 \mathrm{~g})$. Maximum height measured at harvesting time was from plastic mulch treatment with 100 per cent irrigation $(26 \mathrm{~cm})$ while minimum height was obtained from without mulch with 100 per cent treatment $(15 \mathrm{~cm})$. Maximum number of leaves (16) was observed in without mulch treatment with 100 per cent irrigation treatment and minimum leaves in without mulch with 80 per cent irrigation treatment $(10 \mathrm{~cm})$.

- KEY WORDS : Number of branches, Height of plants, Number of leaves

- HOW TO CITE THIS PAPER : Pachore, R.A., Bhukele, S.A., Deshpande, S.S. and Jadhav, S.P. (2019). Effect of different mulching and irrigation scheduling on agronomical parameters of bokchoy. Internat. J. Agric. Engg., 12(1) : 63-72, DOI: 10.15740/HAS/IJAE/12.1/63-72. Copyright@2019: Hind Agri-Horticultural Society. 